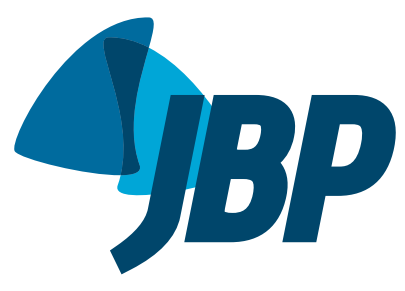

\title{
Staphylococcal superantigen-specific $\lg E$ antibodies: degree of sensitization and association with severity of asthma
}

\author{
José Elabras Filho',2, Fernanda Carvalho de Queiroz Mello², Omar Lupi ${ }^{1,3}$, \\ Blanca Elena Rios Gomes Bica1, José Angelo de Souza Papi', \\ Alfeu Tavares França'
}

1. Serviços de Imunologia Clínica e Reumatologia, Hospital Universitário Clementino Fraga Filho - HUCFF Faculdade de Medicina, Universidade Federal do Rio de Janeiro - UFRJ Rio de Janeiro (RJ) Brasil.

2. Instituto de Doenças do Tórax, Faculdade de Medicina, Universidade Federal do Rio de Janeiro - UFRJ Rio de Janeiro (RJ) Brasil.

3. Serviço de Dermatologia, Hospital Universitário Gaffrée e Guinle, Faculdade de Medicina, Universidade Federal do Estado do Rio de Janeiro UNIRIO - Rio de Janeiro (RJ) Brasil.

\begin{abstract}
Objective: To determine the presence of staphylococcal superantigen-specific IgE antibodies and degree of IgE-mediated sensitization, as well as whether or not those are associated with the severity of asthma in adult patients. Methods: This was a cross-sectional study involving outpatients with asthma under treatment at a tertiary care university hospital in the city of Rio de Janeiro, Brazil. Consecutive patients were divided into two groups according to the severity of asthma based on the Global Initiative for Asthma criteria: mild asthma (MA), comprising patients with mild intermittent or persistent asthma; and moderate or severe asthma (MSA). We determined the serum levels of staphylococcal toxin-specific $\lg E$ antibodies, comparing the results and performing a statistical analysis. Results: The study included 142 patients: 72 in the MA group (median age = 46 years; 59 females) and 70 in the MSA group (median age $=56$ years; 60 females). In the sample as a whole, 62 patients $(43.7 \%)$ presented positive results for staphylococcal toxin-specific IgE antibodies: staphylococcal enterotoxin $A$ (SEA), in 29 (20.4\%); SEB, in 35 (24.6\%); SEC, in 33 (23.2\%); and toxic shock syndrome toxin (TSST), in 45 (31.7\%). The mean serum levels of IgE antibodies to SEA, SEB, SEC, and TSST were $0.96 \mathrm{U} / \mathrm{L}, 1.09 \mathrm{U} / \mathrm{L}, 1.21 \mathrm{U} / \mathrm{L}$, and $1.18 \mathrm{U} / \mathrm{L}$, respectively. There were no statistically significant differences between the two groups in terms of the qualitative or quantitative results. Conclusions: Serum IgE antibodies to SEA, SEB, SEC, and TSST were detected in $43.7 \%$ of the patients in our sample. However, neither the qualitative nor quantitative results showed a statistically significant association with the clinical severity of asthma
\end{abstract}

Keywords: Asthma; Immunoglobulin E; Superantigens; Bacterial toxins; Staphylococcus aureus.

\section{INTRODUCTION}

Staphylococcus aureus is a gram-positive bacterium that can colonize the human skin and respiratory tract. Colonization with $S$. aureus might or might not be associated with pathological processes. S. aureus produces several toxins related to its colonization ability and pathogenicity. The most important are toxic shock syndrome toxin (TSST), staphylococcal enterotoxin A (SEA), SEB, SEC, SED, SEE, SEG, SEH, and SEI, the activities of which include superantigen activity, pyrogenicity, and potentiation of lethality of other toxins. ${ }^{(1-3)}$

The superantigen activity of staphylococcal toxins consists of direct stimulation of class II MHC receptors and $T$ cells, independently of antigen presentation by antigen-presenting cells, stimulating the proliferation and activity of CD4 and CD8 T lymphocytes. This mechanism is related to the worsening of allergic diseases by the production of staphylococcal toxin-specific IgE antibodies, as well as by a direct effect on tissue mast cells, leading to their degranulation. ${ }^{(1-3)}$
In asthma patients, staphylococcal toxins also act as superantigens, stimulating CD4 T Iymphocyte proliferation and activity and leading to an increased production of staphylococcal toxin-specific IgE antibodies, causing an allergic-type reaction by biding to mast cells in the respiratory tract. This reaction results in the release of mediators such as histamine, kinins, platelet-activating factor, and arachidonic acid metabolites (prostaglandins and leukotrienes), as well as of chemokines, eliciting immediate and late inflammatory responses (by the recruitment and activation of neutrophils and eosinophils) and culminating in asthma worsening. ${ }^{(1-3)}$

Staphylococcal superantigens have been shown to play roles in atopic dermatitis, rhinosinusitis, and asthma, being correlated with their severity. ${ }^{(4-8)}$ With regard to asthma, Kowalski et al. found IgE antibodies to SEA, SEC, and TSST in $89.7 \%$ of 237 asthma patients (mean levels of $1.096 \pm 3.25 \mathrm{kU} / \mathrm{L}$ ); although there was no significant difference between those with severe asthma and those with non-severe asthma in terms of the prevalence of

Correspondence to:

José Elabras Filho. Serviço de Imunologia Clínica, Hospital Universitário Clementino Fraga Filho, Universidade Federal do Rio de Janeiro, Rua Rodolpho Paulo Rocco, 255,

Cidade Universitária, Ilha do Fundão, CEP 21941-913, Rio de Janeiro, RJ, Brasil.

Tel./Fax: 5521 3938-2626. E-mail: elabrasfilho@terra.com.br or elabrasfilho@hotmail.com

Financial support: None. 
staphylococcal toxin-specific IgE antibodies (81.4\% vs. $69.2 \%)$, mean levels were higher in the former than in the latter $(1.65 \pm 3.25 \mathrm{kU} / \mathrm{L}$ vs. $0.54 \pm 0.72 \mathrm{kU} / \mathrm{L}) .^{(9)}$ In another study $(\mathrm{N}=210)$, the same authors obtained similar results, the prevalence of staphylococcal toxin-specific IgE antibodies being $76.1 \%$ in patients with severe asthma and $71.1 \%$ in those with non-severe asthma, mean levels being three times higher in the former than in the latter. ${ }^{(10)}$ Bachert et al. found a significant increase in staphylococcal toxin-specific IgE antibodies in patients with severe asthma when compared with those with mild asthma and controls $(N=70) .^{(11)}$ In a more recent study $(N=387)$, the same group of authors found a significant increase in staphylococcal toxin-specific IgE antibodies in patients with severe uncontrolled asthma (59.6\%) when compared with those with controlled asthma (40.8\%) and controls (13.0\%). High levels of staphylococcal toxin-specific IgE antibodies have been found to be a risk factor for asthma $(O R=7.6)$ and severe asthma $(\mathrm{OR}=11.09))^{(12)}$

In Latin America, there have been no studies correlating staphylococcal superantigens with the severity of asthma. Therefore, we investigated a population of asthma patients treated at a university hospital in the city of Rio de Janeiro, Brazil, and having no risk factors for increased staphylococcal colonization or infection in order to correlate the clinical severity of asthma with the presence of staphylococcal toxin-specific IgE antibodies and degree of IgE-mediated sensitization.

\section{METHODS}

\section{Patients}

This was a cross-sectional study including adult patients clinically and functionally diagnosed with asthma and receiving outpatient treatment at the Clementino Fraga Filho University Hospital, located in the city of Rio de Janeiro, Brazil. Between 2009 and 2013, consecutive patients were divided into two groups according to the clinical severity of asthma based on the Global Initiative for Asthma criteria(13-15): the mild asthma (MA) group, comprising patients with mild intermittent or persistent asthma; and the moderate or severe asthma (MSA) group.

According to the Global Initiative for Asthma, ${ }^{(13-15)}$ asthma severity can be evaluated on the basis of the treatment required in order to control the disease. Patients with mild asthma are defined as those requiring only rescue medication, low-dose inhaled corticosteroids/ leukotriene receptor antagonists, or a combination of the two. Patients with moderate asthma are defined as those using long-acting $\beta_{2}$ agonists and inhaled corticosteroids at low or moderate doses. Patients with severe asthma are defined as those using long-acting $\beta_{2}$ agonists and inhaled corticosteroids at high doses or other bronchodilators and anti-inflammatory drugs for asthma control.
The criteria for inclusion in the present study were as follows: being an adult patient clinically and functionally diagnosed with asthma, ${ }^{(16,17)}$ regardless of the presence of rhinitis and positive skin test results to aeroallergens.

The exclusion criteria were as follows: presence of COPD, atopic dermatitis, or both; asthma exacerbation in the last four weeks; presence of respiratory infection or use of antimicrobial agents in the last six weeks; use of systemic corticosteroid therapy for seven or more days in the last four weeks; history of immunodeficiency, neoplasia, connective tissue disease, kidney failure, sinonasal polyposis, chronic sinus disease, cystic fibrosis, or bronchiectasis; pregnancy; smoking in the last twelve months; and declining to participate in the study or give written informed consent.

The sample size calculation was based on a study by Kowalski et al. ${ }^{(9)}$ and was performed with a specific statistical calculation program (OpenEpi). For a paired relationship, with a 95\% confidence interval and a power of $80 \%$, the required sample size was calculated to be 140 (70 per group).

\section{Procedures}

Procedures included the following: clinical history taking; physical examination; routine tests (including blood count, ESR measurement, determination of total IgE levels, parasitological stool examination, chest X-rays, and sinus X-rays); pulmonary function tests (spirometry and PEF measurement); skin prick tests to aeroallergens; and determination of serum levels of IgE antibodies (to SEA, SEB, SEC, and TSST). Spirometry was performed with a spirometer (Jaeger, Würzburg, Germany), in accordance with the American Thoracic Society guidelines ${ }^{(16,17)}$ and the reference values proposed by Knudson et al. ${ }^{(18)} \mathrm{A}$ finding of obstruction and positive bronchodilator test results with reversal or significant improvement were consistent with asthma. ${ }^{(16,17)}$ For PEF measurement, a peak flow meter (Mini-Wright AFS; Clement Clarke International, Essex, England) was used, the reference values being those proposed by Nunn and Gregg. ${ }^{(19)}$ Skin tests to aeroallergens were performed with the use of the puncture technique and standard antigens. ${ }^{(20)}$ For determination of serum levels of staphylococcal toxin-specific IgE antibodies, an immunoassay system (ImmunoCAP ${ }^{\circledR}$ 100; Phadia, Uppsala, Sweden) was used. (21) Values above $0.35 \mathrm{U} / \mathrm{L}$ were considered positive. ${ }^{(21)}$

\section{Statistical analysis}

In order to compare numerical variables, we used the Student's t-test or the Mann-Whitney test, as appropriate, through the analysis of the Kolmogorov-Smirnov and Shapiro-Wilk coefficients. In order to compare categorical variables, we used the chi-square test or Fisher's exact test, as appropriate. The sample size was calculated in order to provide a power of $80 \%$, and values of $p<0.05$ were considered statistically significant. 


\section{Ethical aspects}

The present study was approved by the Research Ethics Committee of the Federal University of Rio de Janeiro Clementino Fraga Filho University Hospital. All participating patients gave written informed consent, and the treatment provided to those who declined to participate in the study was in no way affected by their decision. Data confidentiality and patient anonymity were maintained during data handling and processing.

\section{RESULTS}

A total of 142 patients were studied. Of those, 72 (17 with mild intermittent asthma and 55 with mild persistent asthma) were allocated to the MA group and 70 (53 with moderate asthma and 17 with severe asthma) were allocated to the MSA group. The median age was 52.5 years (46 years in the MA group and 56 years in the MSA group), females and White individuals having predominated. In the sample as a whole, the mean body mass index (BMI) was $27.09 \mathrm{~kg} / \mathrm{m}^{2}, 128$ patients had rhinitis, 131 had positive skin test results to aeroallergens, and 99 had a family history of atopy. Only $37(26.1 \%)$ had a history of smoking. Mean percent predicted PEF was $72.59 \%$, mean percent predicted pre-bronchodilator $\mathrm{FEV}_{1}$ was $71.55 \%$, and mean percent predicted post-bronchodilator $\mathrm{FEV}_{1}$ was $81.48 \%$. Mean eosinophil count was $4.4 \%$, and mean total IgE levels were $574.92 \mathrm{IU} / \mathrm{mL}$. Table 1 shows the distribution of sociodemographic and clinical variables, and Table 2 shows lung function parameters and laboratory findings in the MA and MSA groups.

Of the sample as a whole, 62 patients (43.7\%) tested positive for staphylococcal toxin-specific IgE antibodies: SEA, in 29 (20.4\%); SEB, in 35 (24.6\%); SEC, in 33 (23.2\%); and TSST, in 45 (31.7\%). The mean serum levels of IgE antibodies to SEA, SEB, SEC, and TSST were $0.96 \mathrm{U} / \mathrm{L}, 1.09 \mathrm{U} / \mathrm{L}, 1.21 \mathrm{U} / \mathrm{L}$, and $1.18 \mathrm{U} / \mathrm{L}$, respectively.

As can be seen in Tables 3 and 4, there were no statistically significant differences between the two groups regarding the frequency of IgE-mediated sensitization and serum levels of staphylococcal toxin-specific IgE antibodies.

\section{DISCUSSION}

There were statistically significant differences between the two groups of patients in the present

Table 1. Clinical and sociodemographic characteristics of the study population, by asthma severity. ${ }^{a}$

\begin{tabular}{|c|c|c|c|}
\hline \multirow[t]{2}{*}{ Characteristic } & \multicolumn{2}{|c|}{ Group } & \multirow[t]{2}{*}{ p* } \\
\hline & $\begin{array}{l}\text { Mild asthma } \\
\qquad(\mathrm{n}=72)\end{array}$ & $\begin{array}{l}\text { Moderate or severe asthma } \\
\qquad(\mathrm{n}=70)\end{array}$ & \\
\hline Age, years & $45.51 \pm 15.36$ & $53.59 \pm 12.82$ & $<0.0001$ \\
\hline Weight, kg & $66.17 \pm 13.20$ & $69.36 \pm 15.03$ & 0.2 \\
\hline Height, $\mathrm{cm}$ & $159.23 \pm 8.00$ & $157.1 \pm 7.04$ & 0.12 \\
\hline $\mathrm{BMI}, \mathrm{kg} / \mathrm{m}^{2}$ & $26.15 \pm 5.26$ & $28.06 \pm 5.51$ & 0.03 \\
\hline \multicolumn{4}{|l|}{ Gender } \\
\hline Male & $13(18.1)$ & $10(14.3)$ & 0.54 \\
\hline Female & 59 (81.9) & $60(85.7)$ & \\
\hline \multicolumn{4}{|l|}{ Race } \\
\hline White & $57(79.2)$ & $52(74.3)$ & 0.49 \\
\hline Mulatto or Black & $15(20.8)$ & $18(25.7)$ & \\
\hline Presence of rhinitis & $71(98.6)$ & $57(81.4)$ & 0.001 \\
\hline Family history of atopy & $52(72.2)$ & $47(67.1)$ & 0.51 \\
\hline History of smoking & $17(23.6)$ & $20(28.6)$ & 0.5 \\
\hline Positivity for aeroallergens & $69(95.8)$ & $62(88.6)$ & 0.1 \\
\hline
\end{tabular}

BMI: body mass index. ${ }^{\text {Values expressed as mean } \pm \text { SD or } n(\%) . ~ * S t u d e n t ' s ~ t-t e s t ~(f o r ~ a g e) ~ a n d ~ c h i-s q u a r e ~ t e s t ~}$ or Fisher's test (for the remaining parameters).

Table 2. Lung function parameters and laboratory findings in the study population, by asthma severity. ${ }^{\text {a }}$

\begin{tabular}{|c|c|c|c|}
\hline \multirow[t]{2}{*}{ Characteristic } & \multicolumn{2}{|c|}{ Group } & \multirow[t]{2}{*}{$p^{*}$} \\
\hline & $\begin{array}{l}\text { Mild asthma } \\
\qquad(\mathrm{n}=72)\end{array}$ & $\begin{array}{l}\text { Moderate or severe asthma } \\
\qquad(\mathrm{n}=70)\end{array}$ & \\
\hline PEF, mL & $339.38 \pm 96.51$ & $276.64 \pm 102.11$ & $<0.0001$ \\
\hline PEF, \% & $78.52 \pm 20.40$ & $66.48 \pm 21.65$ & 0.01 \\
\hline Pre-BD FEV ${ }_{1}, \%$ & $80.03 \pm 16.59$ & $62.83 \pm 21.88$ & $<0.0001$ \\
\hline Post-BD FEV $1, \%$ & $90.28 \pm 16.01$ & $72.43 \pm 23.01$ & $<0.0001$ \\
\hline Eosinophils, $n$ & $331.96 \pm 252.94$ & $283.84 \pm 209.93$ & 0.31 \\
\hline Eosinophils, \% & $4.93 \pm 3.63$ & $4.03 \pm 3.23$ & 0.08 \\
\hline IgE, IU/mL & $578.18 \pm 728.68$ & $571.57 \pm 772.11$ & 0.41 \\
\hline
\end{tabular}

BD: bronchodilator. avalues expressed as mean \pm SD. *Student's t-test or Mann-Whitney test. 
Table 3. Frequency of IgE-mediated sensitization to staphylococcal toxins in the study population, by asthma severity.

\begin{tabular}{|c|c|c|c|c|c|c|}
\hline \multirow[t]{3}{*}{$\lg E$} & \multirow[t]{3}{*}{ Result } & \multicolumn{4}{|c|}{ Group } & \multirow[t]{3}{*}{$\mathbf{p}^{*}$} \\
\hline & & \multicolumn{2}{|c|}{$\begin{array}{l}\text { Mild asthma } \\
\quad(n=72)\end{array}$} & \multicolumn{2}{|c|}{$\begin{array}{l}\text { Moderate or severe asthma } \\
\qquad(\mathrm{n}=70)\end{array}$} & \\
\hline & & $\mathbf{n}$ & $\%$ & $n$ & $\%$ & \\
\hline \multirow[t]{2}{*}{ SEA } & positive & 12 & 16.7 & 17 & 24.3 & 0.26 \\
\hline & negative & 60 & 83.3 & 53 & 75.7 & \\
\hline \multirow[t]{2}{*}{ SEB } & positive & 15 & 20.8 & 20 & 28.6 & 0.28 \\
\hline & negative & 57 & 79.2 & 50 & 71.4 & \\
\hline \multirow[t]{2}{*}{ SEC } & positive & 14 & 19.4 & 19 & 27.1 & 0.27 \\
\hline & negative & 58 & 80.6 & 51 & 72.9 & \\
\hline \multirow[t]{2}{*}{ TSST } & positive & 21 & 29.2 & 24 & 34.3 & 0.51 \\
\hline & negative & 51 & 70.8 & 46 & 65.7 & \\
\hline \multirow[t]{2}{*}{ Any toxin } & positive & 31 & 43.1 & 31 & 44.3 & 0.88 \\
\hline & negative & 41 & 56.9 & 39 & 55.7 & \\
\hline
\end{tabular}

SEA: staphylococcal enterotoxin A; SEB: staphylococcal enterotoxin B; SEC: staphylococcal enterotoxin C; and TSST: toxic shock syndrome toxin. *Chi-square test or Fisher's test.

Table 4. Serum levels of staphylococcal toxin-specific IgE antibodies in the study population, by asthma severity.

\begin{tabular}{|c|c|c|c|c|c|c|c|}
\hline \multirow[t]{3}{*}{$\lg E$} & \multicolumn{6}{|c|}{ Group } & \multirow[t]{3}{*}{$p^{*}$} \\
\hline & \multicolumn{3}{|c|}{$\begin{array}{l}\text { Mild asthma } \\
\qquad(n=72)\end{array}$} & \multicolumn{3}{|c|}{$\begin{array}{l}\text { Moderate or severe asthma } \\
\qquad(n=70)\end{array}$} & \\
\hline & Mean & SD & Median & Mean & SD & Median & \\
\hline SEA, U/L & 1.07 & 0.72 & 0.91 & 0.88 & 0.66 & 0.69 & 0.41 \\
\hline SEB, U/L & 1.41 & 1.66 & 0.74 & 0.84 & 0.44 & 0.67 & 0.7 \\
\hline SEC, U/L & 1.16 & 1.14 & 0.5 & 1.25 & 0.98 & 0.71 & 0.43 \\
\hline TSST, U/L & 1.33 & 1.04 & 0.75 & 1.06 & 0.74 & 0.85 & 0.9 \\
\hline
\end{tabular}

SEA: staphylococcal enterotoxin A; SEB: staphylococcal enterotoxin B; SEC: staphylococcal enterotoxin C; and TSST: toxic shock syndrome toxin. ${ }^{*}$ Chi-square test or Mann-Whitney test.

study regarding their clinical and sociodemographic characteristics (including age, BMI, and prevalence of rhinitis). The fact that the patients in the MSA were significantly older than were those in the MA group might be due to the fact that asthma tends to be more severe in older individuals, especially those in whom the onset of asthma occurred at an older age.(13-15) Our finding of a significantly higher BMI in the MSA group is consistent with the literature, obesity having been reported to be a risk factor for and an aggravator of asthma. Recent studies have established a relationship between obesity-induced changes in the gastrointestinal and respiratory microbiome and the etiopathogenesis of obesity-related asthma. ${ }^{(13-15,22)}$ Our finding of a higher prevalence of rhinitis in the MA group suggests that atopy was more common in the MA group than in the MSA group, supporting the concept that atopic manifestations tend to be less common in asthma patients with disease that is more severe. ${ }^{(13-15)}$

With regard to the lung function parameters assessed in the present study, absolute and percent predicted PEF were significantly lower in the MSA group, as were percent predicted pre-bronchodilator $\mathrm{FEV}_{1}$ and percent predicted post-bronchodilator $\mathrm{FEV}_{1}$. These findings were expected and are consistent with the literature, showing the usual correlation between clinical severity and lung function parameters. ${ }^{(13-15)}$

Of the 142 patients studied, 62 (43.7\%) tested positive for staphylococcal toxin-specific IgE antibodies,
IgE antibodies to TSST being the most prevalent. Our findings are different from those of two studies in the literature and similar to those of two other studies. In one study, Kowalski et al. found an $89.7 \%$ prevalence of positivity for staphylococcal toxin-specific IgE antibodies in severe and non-severe asthma patients; in another study, they found a $76.1 \%$ prevalence in patients with severe refractory asthma and a $71.1 \%$ prevalence in patients with non-severe asthma. ${ }^{(9,10)}$ In one study, Bachert et al. found a $38.1 \%$ prevalence of positivity for staphylococcal toxin-specific IgE antibodies in patients with asthma (independently of disease severity) and a $62 \%$ prevalence in patients with severe asthma; in another study, they found a $59.6 \%$ prevalence in patients with severe uncontrolled asthma and a $40.8 \%$ prevalence in patients with controlled asthma, ${ }^{(11,12)}$ the latter prevalence being closer to that found in the present study.

Patients with associated chronic infections or other processes facilitating colonization or infection with $S$. aureus, such as sinonasal polyposis, bronchiectasis, chronic bronchitis, and atopic dermatitis, were not included in the present study. By facilitating colonization or infection with S. aureus, the aforementioned conditions can lead to increased quantities of staphylococcal toxins in the body, resulting in increased IgE-mediated sensitization and, consequently, a heterogeneous population of asthma patients. The studies conducted by Kowalski et al. ${ }^{(9,10)}$ and Bachert et al. ${ }^{(11,12)}$ had no 
such exclusion criteria and included patients with chronic sinus disease and sinonasal polyposis, as was the case with the most recent study by Kowalski et al., ${ }^{(10)}$ who nevertheless found no statistically significant differences between asthma patients with polyposis and those without regarding their levels of staphylococcal toxin-specific IgE antibodies. This might explain the differences between our results and those obtained by the two aforementioned groups of authors regarding the degree of IgE-mediated sensitization. In addition, specific characteristics of our population might have influenced our results. To date, there have been no studies assessing colonization with $S$. aureus in the Brazilian population; therefore, it is currently impossible to determine whether or not it is lower than that in the European population. The same is true for the presence or absence of $S$. aureus in the respiratory microbiome of healthy individuals and asthma patients. It is also impossible to determine whether the allergic immune response to staphylococcal toxins is lower in asthma patients in Brazil than in those in other countries.

In the present study, there were no statistically significant differences between the two groups regarding the frequency of staphylococcal toxin-specific IgE antibodies. The same was true for the serum levels of IgE antibodies to those toxins. Our results are qualitatively similar to but quantitatively different from those obtained by Kowalski et al., $(9,10)$ who found significantly higher levels of staphylococcal toxin-specific IgE antibodies in patients with severe asthma. In addition, our results are qualitatively and quantitatively different from those obtained by Bachert et al. ${ }^{(11,12)}$ These differences are also due to the exclusion criteria used in the present study, which were not used in any of the aforementioned studies, and to specific characteristics of our study population, as previously mentioned.

In the present study, IgE antibodies to SEA, SEB, SEC, and TSST were found in $62(43.7 \%)$ of the 142 asthma patients analyzed, and neither the frequency of staphylococcal toxin-specific IgE antibodies nor the serum levels of those antibodies were associated with the clinical severity of asthma. These results are extremely relevant because this is the first study on this topic in Latin America, the results of which differed from those of previous studies conducted in Europe, indicating a "negative" association.

The limitations of the present study lie in the fact that it was a single-center study conducted at a tertiary care university hospital, in a single demographic area of Brazil. Our primary objective was to evaluate the influence of serum levels of staphylococcal toxin-specific IgE antibodies and their association with asthma severity, meaning that this was not a population prevalence study of IgE sensitization in asthma patients and healthy individuals in our region. If that had been the case, a much larger sample size would have been required, and it would have been impossible to obtain that in a single-center study. Therefore, in the present study, each group served as the control group for the other, without the use of a third group, comprising healthy individuals.

Multicenter studies in Brazil and other Latin American countries are needed in order to determine more accurately the role of IgE-mediated sensitization to staphylococcal toxins as an aggravator of asthma, as well as to determine its prevalence in asthma patients and healthy individuals. Such studies should include asthma patients with and without diseases that can lead to increased colonization or infection with S. aureus.

\section{REFERENCES}

1. Dinges MM, Orwin PM, Schlievert PM. Exotoxins of Staphylococcus aureus. Clin Microbiol Rev. 2000;13(1):16-34, table of contents. http://dx.doi.org/10.1128/CMR.13.1.16-34.2000

2. Bhatia A, Zahoor S. Staphylococcus aureus enterotoxins: a review. J Clin Diagn Res. 2007;1(3):188-97.

3. Derycke L, Pérez-Novo C, Van Crombruggen K, Corriveau M Bachert C. Staphylococcus aureus and Chronic Airway Disease. World Allergy Organ J. 2010;3(8):223-8. http://dx.doi.org/10.1097/ WOX.0b013e3181ecd8ae

4. Heaton T, Mallo D, Venaille T, Holt P. Staphylococcal enterotoxin induced IL-5 stimulation as a cofactor in the pathogenesis of atopic disease: the hygiene hypothesis in reverse? Allergy. 2003;58(3):252 6. http://dx.doi.org/10.1034/j.1398-9995.2003.00088.x

5. Bachert C, Zhang N, Patou J, Zele TV, Gevaert P. Role of staphylococcal superantigens in upper airway disease. Curr Opin Allergy Clin Immunol. 2008;8(1):34-8. http://dx.doi.org/10.1097/ ACl.0b013e3282f4178f

6. Pastacaldi C, Lewis P, Howarth P. Staphylococci and staphylococcal superantigens in asthma and rhinitis: a systematic review and metaanalysis. Allergy. 2011;66(4):549-55. http://dx.doi.org/10.1111/j.1398 9995.2010.02502.x

7. Song WJ, Jo EJ, Lee JW, Kang HR, Cho SH, Min KU, et al Staphylococcal enterotoxin specific IgE and asthma: a systematic review and meta-analysis. Asia Pac Allergy. 2013;3(2):120-6. http:// dx.doi.org/10.5415/apallergy.2013.3.2.120

8. Tomassen P, Jarvis D, Newson R, Van Ree R, Forsberg B, Howarth $B$, et al. Staphylococcus aureus enterotoxin-specific lgE is associated with asthma in the general population: a GA(2)LEN study. Allergy.
2013;68(10):1289-97. http://dx.doi.org/10.1111/all.12230

9. Kowalski ML, Cieslak M, Perez-Novo C, Bachert C. Association of Staphylococcus aureus sentizitation with severe asthma. J Allergy Clin Immunol. 2008;121(2) Suppl 1:S199. http://dx.doi.org/10.1016/j. jaci.2007.12.741

10. Kowalski ML, Cieslak M, Pérez-Novo C, Makowska JS, Bachert C. Clinical and immunological determinants of severe/refractory asthma (SRA): association with Staphylococcal superantigen-specific IgE antibodies. Allergy. 2011;66(1):32-8. http://dx.doi.org/10.1111/j.1398 9995.2010.02379.x

11. Bachert C, Gevaert P, Howarth P, Holtappels G, van Cauwenberge $P$, Johansson SG. IgE to Staphylococcus aureus enterotoxins in serum is related to severity of asthma. J Allergy Clin Immunol. 2003;111(5):1131-2. http://dx.doi.org/10.1016/S0091 6749(03)70044-X

12. Bachert C, van Steen K, Zhang N, Holtappels G, Cattaert T, Maus $B$, et al. Specific lgE against Staphylococcus aureus enterotoxins: An independent risk factor for asthma. J Allergy Clin Immunol. 2012;130(2):376-81.e8. http://dx.doi.org/10.1016/j.jaci.2012.05.012

13. Global Initiative for Asthma. Global Strategy for Asthma Management and Prevention, Global Initiative for Asthma 2004. Bethesda: National Institutes of Health. National Heart, Lung and Blood Institute; 2004. p.1-182.

14. Global Initiative for Asthma. Global Strategy for Asthma Management and Prevention, Global Initiative for Asthma 2006. Bethesda: National Institutes of Health. National Heart, Lung and Blood Institute; 2006. p.1-92.

15. Global Initiative for Asthma. Global Strategy for Asthma Management 
and Prevention, Global Initiative for Asthma 2014. Bethesda: National Institutes of Health. National Heart, Lung and Blood Institute; 2014 p.1-132.

16. Standardization of Spirometry, 1994 Update. American Thoracic Society. Am J Respir Crit Care Med. 1995;152(3):1107-36. http:// dx.doi.org/10.1164/ajrccm.152.3.7663792

17. Miller MR, Hankinson J, Brusasco V, Burgos F, Casaburi R, Coates A, et al. Standardisation of spirometry. Eur Respir J. 2005;26(2):319-38. http://dx.doi.org/10.1183/09031936.05.00034805

18. Knudson RJ, Lebowitz MD, Holberg CJ, Burrows B. Changes in the normal maximal expiratory flow-volume curve with growth and aging. Am Rev Resp Dis. 1983;127(6):725-34.

19. Nunn AJ, Gregg I. New regression equations for predicting peak expiratory flow in adults. BMJ. 1989;298(6680):1068-70. http:// dx.doi.org/10.1136/bmj.298.6680.1068

20. Malling HJ. Methods of skin testing. Allergy. 1993;48(Suppl 10):55-6. http://dx.doi.org/10.1111/j.1398-9995.1993.tb04757.x

21. ImmunoCAP Phadia 100 Informative. Uppsala, Sweden: Phadia; 2009. p. 1-52

22. Cho $Y$, Shore SA. Obesity, Asthma, and the Microbiome. Physiology (Bethesda). 2016;31(2):108-16. http://dx.doi.org/10.1152/ physiol.00045.2015 